\title{
IJTARP
}

\section{States of Self as Agents of Self-Killing: An Egogram- based Suicide Note Analysis Study in Russia}

\author{
(C) 2018 Dmitri I. Shustov, Olga D. Tuchina, Tatiana V. Agibalova, \\ Nadezhda L. Zuykova
}

\begin{abstract}
The article presents findings of the egogram-based suicide note analysis, which was undertaken by three experts (MDs, PhDs, certified in TA) in a sample of 26 people (36 suicide notes) in Ryazan, Russia, in 2000 and 2017. The results of the study imply that the presuicidal intrapersonal activity is quite diverse and evolving, and may vary between those who complete suicide lethally and those who survive their suicide attempt. Lethal suicides were characterised by elevated levels of Adult and Adapted Child whereas non-lethal suicide attempts showed an apparent increase in Adapted Child and negative Controlling Parent levels. The authors inferred that suicidal individuals with serious lethal intent might maintain moderate levels of Adapted Child (suffering) so as to enable Adult to accumulate energy needed to perform a fatal suicide attempt. In attempted suicides, high levels of negative Controlling Parent targeting relevant others may diffuse the energy necessary for completion of suicide. Attempted suicide egograms were illustrative of the manipulative nature of the nonlethal suicide attempts, whereas completed suicides did not. Egograms of non-lethal suicide attempts and intoxicated completed suicides had similar distribution of ego state levels, which may reflect the effect of alcohol interfering with the activity of protective Parental substructures and strengthening the role of the negative Controlling Parent targeting either one's inner self or relevant others.
\end{abstract}

\section{Key Words}

transactional analysis, suicide, suicide note, presuicidal syndrome, suicidal state of mind, alcohol use disorders, egogram, ego states

\section{Introduction}

Suicide note analysis is a most important research method to gain insight into the suicidal state of mind.
Transactional Analysis has unique methodological tools and language that may become the foundation of a clinically relevant type of suicide note analysis, the results of which may be useful for planning and carrying out treatment of suicidal individuals as well as assessing suicidal risk and preventing repeated suicide attempts.

Eric Berne (1964) proposed that the structure of personality encompasses three ego states - Parent $(P)$; Adult (A), and Child (C) (definitions of the ego states (both structural and functional models) may be found elsewhere, see Tilney 1998; Stewart \& Joines, 2012). These intrapersonal structures may exhibit themselves functionally (behaviourally as described by Berne) as Controlling Parent (CP, negative NCP and positive $\mathrm{PCP}$ ); Nurturing Parent (NP, negative NNP and positive PNP), Adult (A), Adapted Child (AC), and Free Child (FC). The authors assumed that suicide notes would reflect functional manifestations of ego states, which could then be indicated as egograms (Dusay, 1977).

The study results confirmed this and allow us to make suggestions about how such information can be used to guide the process of psychotherapy with potential suicidees.

\section{Background}

The incidence of leaving suicide notes varies from 3 to 42\% (Paraschakis, Michopoulos, Douzenis, Christodoulou, Koutsaftis \& Lykouras, 2012), grossly reflecting cross-cultural diversity of populations (O'Donnell, Farmer \& Catalan, 1993; Shioiri, Nishimura, Akazawa, Abe, Nushida, Ueno, KojikaMaruyama \& Someya, 2005). Suicide notes fulfill various functions, serving as evidence of voluntary death to the authorities; communicating the individual's last will to the relatives (Sinyor, Schaffer, Hull, Peisah, Shulman, 2015), and being a source of 
knowledge about the suicidal state of mind to researchers (Pestian, Pawel Matykiewicz \& Linn-gust, 2012).

Summarising his brilliant insight into the suicidal state of mind, the father of modern suicidology, Edwin Schneidman (1985, 2005), described the ten commonalities of suicide. Among those, he singled out the common stimulus (intolerable psychological pain); common emotion (hopelessness-helplessness); common cognitive and perceptual states (ambivalence and constriction, correspondingly). Ringel's (1976) concept of 'the presuicidal syndrome' emphasised similar cognitive and emotional experience of a suicidal individual: increasing personal-situative and dynamic-affective constraint; rigidity of perception, association, behaviour patterns, affect and defense mechanisms; narrowing of interpersonal relationships and sense of values; inhibition of aggressive feelings and directing them to one's own self (autoaggression); feelings of isolation; and suicidal fantasies that occur spontaneously, beyond the person's control. Similar to Shneidman (1985), Valach, Young \& Michel (2011) believed that people on the edge of suicide experienced unbearable psychological pain (psychache) associated with altered consciousness, dissociation, automatisms, and analgesia, which prompted suicide action as an attempt to sustain one's identity and positive self-image. Skogman Pavulans, Bolmsjo, Edberg Kidder \& Öjehagen (2012) considered an "acute suicidal state of mind" as the experience of "being past the point of no return" (p. 8). Having analyzed suicide attempters' narratives regarding their road to suicide and actual suicide attempt, Skogman Pavulans et al. (2012) singled out two types of 'the acute suicidal state of mind' in suicide survivors: (1) chaos, and (2) tunnel vision and turned off emotions. The researchers believed these types of the suicidal states of mind to reflect either suicide attempters' efforts to regain control or their loss of control as consistent with Lakeman \& Fitzgerald's (2008) view that suicide may be both a failure to cope and a means of coping. Indeed, the findings of the aforementioned study indicated that "warning signs could be when a person with suicide ideation expresses a view of endless suffering and shows signs of exhaustion and desperation, or if a person who has expressed severe suffering and the view of being stuck in his or her problems suddenly and inexplicably seem perfectly calm" (Skogman Pavulans et al. 2012, p. 9).

Shneidman believed suicidal notes to be the golden source to the suicidal mind because of "a vital reciprocity between suicide notes and the lives of which they are a part" (Leenaars, 2010, p.10). Being illustrative of interpersonal communication patterns, intrapersonal psychodynamics and specific features of the suicidal state of mind, suicide notes may as well be used to identify warning signs of suicide and to provide relevant and timely help to those who are on the edge of it, given that they are in ongoing therapy (Leenaars, Lester, Lopatin, Shustov \& Wenkstern, 2005).

Having analyzed a series of cross-cultural empirical studies, Leenaars (Leenaars, 1988, 1989; O'Connor \& Leenaars, 2004) proposed a thematic model that could be used for theoretical analysis and understanding of suicide. Leenaars' theoretical-conceptual analysis includes 8 clusters (clusters 1 to 5 are intrapersonal and clusters 6 to 8 are interpersonal): (1) unbearable psychological pain; (2) cognitive constriction (rigidity of thinking; tunnel vision; focused attention); (3) indirect expressions (ambivalent feelings, ambiguous attitudes; acting-outs; unconscious processes); (4) inability to adjust (comorbid mental conditions; feeling weak and unable to cope), (5) ego (lack of ego strength); (6) disturbed interpersonal relations (frustrated attachment needs); (7) rejectionaggression (loss as the main theme of suicide; suicide as killing of individual's self); (8) identificationegression (escape as a result of a frustrated need of identification with an abandoning or rejecting object).

However, there is much controversy about whether or not findings that are obtained for suicide note leavers may be generalised beyond this study group, as there are some limitations to this, including the generally lower incidence of suicide note leavers as compared to non-leavers (Cerel, Moore, Brown, van de Venne \& Brown, 2014; Haines, Williams \& Lester, 2011). In a large US epidemiological study comparing 9,048 note leavers to 21,522 other suicides, note writers differed from other suicides in most demographic variables, stressful life events, psychiatric issues, and methods of suicide (Stack \& Rockett, 2016). On the contrary, a comparable survey in Australia found out that the population of suicide note leavers were 'remarkably similar' to other suicides, even though the researchers reported some differences as to gender, race, method and comorbid mental illness (Carpenter, Bond, Tait, Wilson \& White, 2016). Callanan \& Davis (2009) also emphasised essential similarity between the two populations for research purposes.

For another thing, writing their presuicidal narratives, people may experience major cognitive distortions (Jekkel \& Tringer, 2004; Jager-Hyman, Cunningham, Wenzel, Mattei, Brown \& Beck, 2014) and may constrain themselves by self-deception, false memories, misunderstanding of one's motives, and wish to induce a certain response in readers (Leenaars et al, 2005).

Suicide is commonly viewed on a continuum from completed suicide through suicide attempts (genuine or suicidal gestures) to other deliberate self-harm (such as risky behaviours or substance abuse (see Shustov Tuchina, Novikov \& Fedotov, 2016). They differ in terms of lethality, severity of injury, and pres- 
ence or lack of conscious intent to die. Whereas genuine suicide attempts are operationalised as "potentially self-injurious behavior with a nonfatal outcome, for which there is evidence (either implicit or explicit) that the person intended at some (nonzero) level to kill himself/herself" (O'Carroll, Berman, Maris \& Moscicki, 1996, p. 247 - cited from Nock \& Kessler, 2006, p. 616), a suicide gesture is "self-injury in which there is no intent to die, but instead an intent to give the appearance of a suicide attempt in order to communicate with others" (Nock \& Kessler, 2006, p. 616). These definitions emphasise the interpersonal nature of nonfatal suicide attempts. Indeed, Lester (2009) suggested that attempted suicides need to be conceptualised in terms of their own theory rather than in terms of complete suicide theories. He reviewed several possible sociological and psychological theories of attempted suicide, which viewed attempted suicide basically as some kind of communication: (1) desperate attempts to communicate distress to others and to manipulate their behaviour in Taylor's (1982) appeal suicides; (2) use of attempted self-aggression as a means of reaching out to others in Platt's (1985) subcultural theory; (3) a communication to significant others - a cry for help in a Durkheimian theory of attempted suicide proposed by Lester.

From this perspective, a suicide note may become a relevant source for understanding a message beyond a suicide attempt, be it genuine or instrumental (manipulative). For example, Handelman \& Lester (2007) found out that notes from completed suicides had more signs demonstrating isolation, and a lack of belongingness, and fewer metaphysical references than did the notes from attempted suicides, whereas the suicide notes from the attempted suicides indicated greater distress. Interestingly, the survivors' notes had fewer positive emotions, fewer social references, fewer future tense verbs, and more metaphysical references. Handelman \& Lester (2007) inferred that the attempted suicides were experiencing greater mental pain and could be more concerned with their own present condition and less concerned with others. On the other hand, testing his interpersonal theory of suicide, Joiner and colleagues (Joiner, Pettit, Walker, Voelz, Cruz, Rudd \& Lester, 2002) found out that perceived burdensomeness (i.e. a sense of being a burden on someone), as reflected in the suicide notes, correlated strongly with the completer rather than attempter status. The finding remained valid even after controlling for other variables such as gender, controlling feelings, controlling others, general emotional pain, and hopelessness. However, Lester \& Gunn (2012), in a larger sample of suicide notes, failed to confirm the presence of perceived burdensomeness, and hence the validity of Joiner's theory as applied to completed suicide.
Undoubtedly, understanding a suicide attempt as an act of interpersonal communication or as a transaction in TA terms may have important clinical implications. Quite a few TA authors theorised that it was the Don't Be/Don't Exist injunction that laid the basis for suicidality (Holloway 1973; Drye, Goulding \& Goulding, 1973; Steiner, 1974; Schustov \& Lester, 1999; White, 2017). According to White (2011), the Don't Exist decision gives rise to a group of 7 suicidal decisions, 2 of which are manipulative ("If you don't change, I will kill myself"; "I will almost die (over and over) to get you to love me"); and the remaining 4 contain some kind of a communicative message to others ("I will show you even if it kills me"; "I will get you to kill me"; "I will kill myself by accident"; "I will kill myself to hurt you"). "If things get too bad, I will kill myself" may be the only decision for which the interpersonal and communicative nature is less obvious, and it may as well reflect the state of unbearable mental pain that is believed to be the main precursor of suicide (see above).

Shustov $(2000 ; 2005)$ carried out a series of studies to empirically test the assumption that the Don't Exist injunction underlies auto-aggression (self-destructive behaviours) in people with alcohol dependence (AD) (see Shustov et al 2016 for a brief review of the research). He hypothesised that auto-aggression in people with $A D$ might actualise both through suicidal (suicides and suicide attempts) and non-suicidal (family system collapses; persistent somatic illness; risky behaviours; antisocial behaviours; professional failures etc.) behaviours. Shustov (2000) analyzed 256 cases of completed suicide ( $48 \%$ of alcoholic suicides; $38.4 \%$ of cases with no diagnosed psychopathology; $4 \%$ of cases with schizophrenia; $10.6 \%$ of cases with other psychopathology). He found out that alcoholic suicides had a number of specific features as compared to non-alcoholic suicides: younger age of suicide (36-49 y.o.) and a decrease in suicides after the age of $50 \mathrm{y} .0$. versus the peak of suicides at the age of 55-59 y.o. and an increasing trend after the age of 59 y.o. in the general population; stronger correlation of suicide with divorces and unemployment; lack of a 'serious' reason for suicide (according to relatives). Nevertheless, the theoretical-conceptual analysis of suicide notes revealed striking similarities between alcoholic and non-alcoholic suicides as far as the presuicidal state of mind was concerned (Shustov 2005). These findings may imply that suicidal phenomena may indeed have common psychodynamic grounds. For example, guiding himself by Campbell's (1999) and Gabbard's (2003) works and his own clinical/supervisory experience, Little (2009) assumed that the main characteristic of the presuicidal state of mind was the suicidal fantasy which represented "a solution to a conflict that results from 
the wish to merge with the mothering object, on the one hand, and the primitive anxieties about annihilation of the self, on the other" (p. 222-223). He also asked a crucial question, "Who wants to kill whom?" or "Which ego state wishes to kill which ego state?" (p. 219); by answering this we may be better able to understand the presuicidal and suicidal psychodynamics, both from the intrapersonal (in case of completed suicides and genuine suicide attempts) and interpersonal (in case of more manipulative attempted suicides) perspectives.

TA analysts have various tools that may allow them to answer these questions and for studying the evolving nature of self, its dynamics and change, both immediately before suicide and while preparing for self-killing, or maybe even during a suicide attempt (in non-lethal cases). However, to our knowledge, these tools have not been operationalised and used for research purposes. We believe that these tools may be successfully integrated with traditional suicidological instruments such as suicide note analysis. Practical implications of suicide note analysis for therapy with suicidal clients cannot be underestimated as it might lay the basis for developing specific tactics of therapy and suicide risk assessment that would match the person's presuicidal state of mind. For example, White (2011) saw suicide notes as important tools to understand the type of suicidal decision. He drew clinicians' attention to the importance of considering several factors while analyzing suicide notes, such as how the suicide note was obtained (e.g. after the death or just in time to preclude the attempt) and the period when it was written (e.g. immediately prior to suicide or in advance). Being indicative of the quality of the person's presuicidal state of mind, suicide notes may be quite useful for clinical assessment and prevention, as they may inform the therapist whether the client is re-experiencing the same psychodynamics at the moment.

\section{Objective}

The overall goal of this study was to identify the psychodynamics of the presuicidal state of mind using a TA-based method of suicide note analysis that would take into account the dynamic nature of the changing self immediately prior to suicide.

Hypothesis 1 to be checked by this study suggested that the contrastive analysis of the suicide notes in completed versus attempted suicide; alcoholic versus non-alcoholic suicide, and intoxicated versus sober suicide might reveal differences between the presuicidal states of mind in these samples.

Hypothesis 2 was that these differences might contribute to identification of predictors of suicide attempt fatality.
According to our null hypotheses, (1) the suicidal state of mind would be static (represented by one ego state) rather than dynamic, and (2) the variance between completers and attempters as far as their psychodynamics is concerned would be statistically insignificant.

\section{Funding Sources}

The study recruited no additional funding beyond the regular institutional budget (Ryazan State Medical University) allocated for research purposes to the Psychiatry Department.

\section{Ethical Considerations}

The study was approved by the local ethical committee. We have changed all names and places in the texts of the suicide notes that are quoted here so as to protect confidentiality and the rights of the people mentioned. The suicide attempters who survived the suicide provided an informed consent for participating in the study and publishing its findings.

\section{Methodology}

\section{Methods}

The study was carried out by employees of the Psychiatry Department, I.P. Pavlov's State Medical University, (Ryazan, Russia); Moscow Research and Practical Centre for Narcology (Note: a Russian term for Addiction Medicine) of the Department of Public Health, (Moscow); and Peoples' Friendship University of Russia (Moscow) in 2000 and 2017. It is based on the findings and materials of a larger study of 256 lethal suicide attempts that took place in 1994 Shustov (2000). As of the outset of the study, the criminal investigation confirmed these deaths to be suicides, and researchers were granted access to the materials of the corresponding dismissed criminal cases.

We examined 28 suicide notes left by 22 people in the completed suicide sample. The comparison group of attempted suicides included 8 suicide notes by 4 people who were receiving treatment at the outpatient department of Ryazan psychiatric hospital because of a suicide attempt in 2000 .

For the purposes of the study, we used a specific method of suicide note analysis that rested on the TA method of egograms (Dusay, 1977) and was proposed by Schustov (1997). It should be mentioned that suicidology offers a number of approaches to analyzing suicide notes, such as descriptive, classification, content and theoretical-conceptual analysis (TCA) which are sometimes embedded in advanced computational algorithms for research and, more rarely, clinical care purposes (Pestian, Nasrallah, Matykiewicz, Bennett \& Leenaars, 2010). These methods are highly informative as far as epidemiological and theoretical research into the risk factors, reasons and motives for suicide is concerned 
but would have had a limited instrumentality in terms of our study as they did not allow for assessing the dynamic changes in the presuicidal self.

The egogram-based suicide note analysis rested on the assumption that every statement in a suicide note reflected certain dynamic intrapersonal changes occurring at the moment of writing and being indicative of a certain state of self.

The concept of ego states (Berne 1964) fit well with the purposes of assessing presuicidal states of self and provided a fully-fledged conceptual framework for choosing egograms (Dusay 1977) as a TA-based method of suicide note analysis. Schustov (1997) modified Dusay's method for analyzing written accounts based on their objective characteristics. To improve reliability of the method, which originally employed a single-expert assessment, the authors of this study arranged participation of three raters of equal academic level (MD, PhD) and internationally certified in TA (Teaching \& Supervising Transactional Analyst (Psychotherapy), Provisional Teaching \& Supervising Transactional Analyst (Psychotherapy), and Certified Transactional Analyst (Psychotherapy). The experts carried out the egogram-based analysis observing the following protocol:

1. As some suicide attempters presumably wrote several suicide notes at one time (unless it was a single note), all suicide notes authored by one person accounted for one text.

2. The length of the whole text was measured in centimeters and equated to $100 \%$.

3. The length of the statements made by different ego states (CP (positive (PCP) and negative (NCP)); NP (positive (PNP) and negative (NNP)); A; AC; FC) was measured separately.

4. The experts calculated the ratio (\%) of separate ego state statements to the whole text $(100 \%)$, and drew an egogram reflecting these ratios (e.g. Figures 1 and 2).

After the experts had completed their analysis, the levels of ego states were averaged for every comparison group, and corresponding egograms were drawn and compared.

\section{Statistical analysis}

The authors calculated regular descriptive statistics for sociodemographic data such as age (mean scores (M); standard deviations (SD); minimum and maximum scores). The authors tested the type of distribution for the functional ego state levels (the Kolmogorov-Smirnov test), and as the data failed to have normal distribution, they employed nonparametric measures for further analysis. Due to the same reason, the authors used median scores (rather than mean scores), and the $25^{\text {th }}$ and $75^{\text {th }}$ percentiles (as a measure of dispersion) to assess average levels of ego state functioning.

The Mann-Whitney $U$ test was used to assess statistical significance of differences between the comparison groups. Agreement among raters was assessed using Kendall's coefficient of concordance (W). The Kruskal-Wallis test was used to confirm the existence of significant differences among ego state levels within samples.

The null hypotheses were rejected when the significance of differences between groups amounted to $p<0.05$.

\section{Rater consistency}

In order to check the agreement between experts, we used the Kendall's coefficient of concordance (Table 1 ), as the heterogeneity of findings resulting from large differences in expert assessments might have presented a threat to the internal validity of the study. The experts' ratings of almost all variables were homogenous, so their judgements regarding the levels of the ego states prior to the suicide may be considered reliable. Heterogeneity of PCP and PNP ratings may be explained by the fact that the experts identified these positive ego states in suicide notes rarely and these scores were distributed quite inconsistently.

\begin{tabular}{|c|c|l|}
\hline Variable Test & Kendall's W & P \\
\hline A & .689 & .001 \\
\hline AC & .581 & .012 \\
\hline FC & .647 & .003 \\
\hline PCP & .422 & .169 \\
\hline NCP & .682 & .002 \\
\hline PNP & .415 & .185 \\
\hline NNP & .503 & .049 \\
\hline
\end{tabular}

Bold type: raters' scores are concordant $(p<0,05)$

Table 1. Agreement between raters

\section{Sample/Subjects/Participants}

The sample totalled 36 suicide notes by 26 people, who represented $8.6 \%$ of all registered criminal cases $(\mathrm{N}=276)$ over the studied period (1994) (Shustov 2005). There was no significant statistical difference between the suicide note leavers and the general sample as to the main sociodemographic variables (age, sex, race etc.); mental illness; motives for suicide, etc., which was consistent with other findings (Carpenter, et al., 2016). There were statistically insignificant trends of higher incidence of suicide note leaving in people with alcohol use disorders (AUD) $(10.6 \%$ versus $6 \%)$, and lower incidence of suicide note leaving in people exhibiting signs of social 
isolation and loneliness ( $7 \%$ versus $12.5 \%)$. The latter result may be quite consistent with the idea that suicide notes aim at conveying a personally relevant message to important others.

The whole sample was divided into groups of completed and attempted suicides (Table 2, A). The completed suicide group included 28 suicide notes by 22 people (17 men and 5 women). 8 of them had no diagnosis of mental disorder, 13 people had alcohol use disorder (AUD) and 1 person suffered from schizophrenia.

Based on the objective information provided by authorities, medical documentation, and findings of the psychological autopsy, the completed suicide group $(\mathrm{N}=22)$ was eventually divided into the subgroups of alcoholic $(\mathrm{N}=13)$ versus non-alcoholic suicides $(\mathrm{N}=9)$ (Table 2, B), and intoxicated $(\mathrm{N}=4)$ versus sober $(\mathrm{N}=18)$ suicides (Table 2, $\mathrm{C})$. Intoxicated subjects included three people with AUD, and 1 person without mental diagnosis. In order to include the case in the alcoholic suicide subgroup, we looked for signs of alcohol withdrawal syndrome, long periods of heavy drinking, binge drinking; social and family problems relating to the use of alcohol; and evidence for AUD treatment attempts.

The attempted suicide group (suicide survivors) included 8 suicide notes by 4 women $(2$ - mentally healthy; 1 - diagnosed with schizophrenia and 1 diagnosed with bipolar affective disorder) who survived their suicide attempt. The average age of completed suicides was 45.4 y.o. ( $S D=3.4)$, and 54.5 y.o. $(S D=8.3)$ in attempted suicides.

\section{Results}

Table 2 and the corresponding egograms (Figures 1 to 6) illustrate distribution of the ego state activity in completed and attempted suicides according to the experts' assessment.

The completed suicide and the attempted suicide egograms that were drawn based on the raters' assessments looked dramatically different (Figures 1 and 2). Quite paradoxically, completed suicides had higher A levels (i.e. statements that the experts believed to reflect A's activity) and much lower AC and NCP levels as compared to attempted suicides. Nevertheless, the Mann-Whitney $U$ test identified statistically significant differences only for the NCP (3.4 $\vee 33.8 ; p=.048)$ and PNP levels $(4.4 \% \vee 0 \%$; $\mathrm{p}=.048)$. Lack of statistically significant differences between $A$ and $A C$ levels may relate to the small sample size.

Most notes comprised statements by several ego states. In completed suicides, practically all ego states (A, PCP, PNP, FC; NCP, NNP, AC) were constantly present, whereas attempted suicide egograms lacked positive ego state activity (i.e. PNP and PCP). It should be noted that the levels of FC in attempted suicide may not be informative as it was detected only in one person by one expert (although the level identified was quite high). Single ego state suicide notes accounted for $13.8 \%$ (3 people) of all cases only, and reflected A's or AC's functioning.

Adult. Although we expected to see high levels of AC and NCP in completed suicides, the higher level of Adult ego state was quite surprising. Adult exhibited itself in instructions, last will, instrumental advice as to what to do with the body after one's death; how to behave, whom to inform or to contact (colleagues, neighbours, relatives); where to get a coffin, etc. It engaged in habitual activity of planning the future and communicating with others.

\section{Examples:}

"Phone the station tomorrow in the morning to inform Kazankov and Ivannikov. They will help [you]";

"Val, don't send me away to the mortuary, rather phone Jake, and he will find a way for me to lie home" (Please note that according to the Orthodox tradition, the deceased person's body is being kept either at the mortuary or at home during three days before the funeral).

The Adult levels in the completed suicide group were twice as high as in the attempted suicide group (34.8\% v $14.8 \%$ ).

\section{Negative ego states: NCP; NNP}

NCP levels in the attempted suicide group exceeded the NCP levels in the completed suicides $(p=0.048)$. In most cases, the survivors' NCP statements comprised accusations and manipulative ulterior transactions. Examples of NCP in the survivors' notes:

"Kate! Why did you tell my daughter that nonsense that I told you about her you asked why she didn't help me

I told you I didn't know <...> and why did you tell her my neighbors are bad, dina from apartment 39.

\section{Shame on you"}

"You can't understand this <.... > Have a better life than I did"

On the contrary, in the completed suicide notes, NCP exhibited itself in persecutory and derogatory statements directed at the individual's own self. This may mean that the suicide completers did not attempt manipulating relevant others through their suicide attempts.

Examples of NCP in the completed suicide notes:

"we are too simple and ingenuous we'd better be cleverer" 


\begin{tabular}{|c|c|c|c|c|c|c|c|c|c|}
\hline \multicolumn{3}{|c|}{ Suicide Type } & A & $A C$ & FC & $+\mathrm{CP}$ & $-\mathrm{CP}$ & $+\mathrm{NP}$ & $-N P$ \\
\hline \multirow{18}{*}{ A } & \multirow{9}{*}{$\begin{array}{r}\text { Completed suicides } \\
\qquad(\mathrm{N}=22)\end{array}$} & $\mathrm{M}$ & 40.7 & 29.8 & 2.6 & 0.8 & 9.5 & 9 & 7.2 \\
\hline & & SE & 6.7 & 6 & 1.4 & 0.4 & 2.8 & 2.6 & 2.9 \\
\hline & & SD & 31.2 & 27.8 & 6.4 & 1.8 & 13.3 & 12.2 & 31.2 \\
\hline & & Range & 100 & 100 & 29.5 & 6 & 47.6 & 46.2 & 55.6 \\
\hline & & Min & 0 & 0 & 0 & 0 & 0 & 0 & 0 \\
\hline & & Max & 100 & 100 & 29.5 & 6 & 47.6 & 46.2 & 55.6 \\
\hline & & $\mathrm{Me}$ & 34.8 & 27.5 & 0.5 & 0.4 & $3.4^{\star}$ & $4.4^{\star}$ & 2.3 \\
\hline & & \multirow{2}{*}{$\begin{array}{ll}\text { Pr. } & 25 . \\
& 75 . \\
\end{array}$} & 15.4 & 6.6 & 0 & 0 & 0.3 & 0.2 & 0.2 \\
\hline & & & 65.5 & 43.1 & 2.2 & 1.3 & 16.5 & 13.1 & 8.4 \\
\hline & \multirow{9}{*}{$\begin{array}{l}\text { Attempted suicides } \\
\qquad(\mathrm{N}=4)\end{array}$} & $\mathrm{M}$ & 13.4 & 36 & 1.6 & 0 & 37.1 & 0 & 10.5 \\
\hline & & SE & 5.2 & 7.3 & 1.6 & 0 & 15.9 & 0 & 8.3 \\
\hline & & SD & 10.3 & 14.6 & 3.2 & 0 & 31.8 & 0 & 16.5 \\
\hline & & Range & 22.3 & 28.7 & 6 & 0 & 64 & 0 & 35 \\
\hline & & Min & .83 & 20.4 & 0 & 0 & 8 & 0 & 0 \\
\hline & & Max & 23.1 & 49.1 & 6 & 0 & 73 & 0 & 35 \\
\hline & & $\mathrm{Me}$ & 14.8 & 37.1 & 1.6 & 0 & $33.8^{\star}$ & $0^{*}$ & 3.5 \\
\hline & & \multirow{2}{*}{$\begin{array}{ll}\text { Pr. } & 25 . \\
& 75 . \\
\end{array}$} & 5 & 23.5 & - & - & 10.2 & - & 0.53 \\
\hline & & & 21.7 & 48.4 & 4.8 & - & 63.9 & - & 20.5 \\
\hline \multirow{18}{*}{ B } & \multirow{9}{*}{$\begin{array}{r}\text { Alcoholic suicides } \\
\text { (completed) } \\
(\mathrm{N}=13)\end{array}$} & $\mathrm{M}$ & 41.8 & 21.9 & 1.9 & 0.79 & 12.3 & 11.2 & 9.3 \\
\hline & & SE & 9.2 & 6.3 & 0.8 & 0.451 & 4.3 & 4.1 & 4.63 \\
\hline & & SD & 33 & 22.8 & 2.8 & 1.6 & 15.7 & 14.6 & 16.7 \\
\hline & & Range & 100 & 71.3 & 7.7 & 4 & 47.6 & 46.2 & 55.6 \\
\hline & & Min & 0 & 0 & 0 & 0 & 0 & 0 & 0 \\
\hline & & Max & 100 & 71.3 & 7.7 & 4 & 47.6 & 46.2 & 55.6 \\
\hline & & $\mathrm{Me}$ & 40.1 & 18.4 & 0 & 0 & 8.2 & 4.5 & 2.3 \\
\hline & & Pr 25. & 12 & 0 & 0 & 0 & 0 & .3 & 0 \\
\hline & & 75. & 70 & 38.2 & 4.3 & 0.85 & 24.5 & 18.9 & 10.5 \\
\hline & \multirow{9}{*}{$\begin{array}{r}\text { Non-alcoholic suicides } \\
\text { (completed) } \\
(\mathrm{N}=9)\end{array}$} & $M$ & 39.2 & 41.2 & 3.6 & $\begin{array}{l}0.7 \\
\end{array}$ & 5.5 & 5.7 & 4.1 \\
\hline & & SE & 10.1 & 10.5 & 3.2 & 0.7 & 2.6 & 2.3 & 2.1 \\
\hline & & SD & 30.4 & 31.5 & 9.7 & 2.1 & 7.9 & 7 & 6.4 \\
\hline & & Range & 100 & 100 & 29.5 & 6 & 21.5 & 16.7 & 19.4 \\
\hline & & Min & 0 & 0 & 0 & 0 & 0 & 0 & 0 \\
\hline & & Max & 100 & 100 & 29.5 & 6 & 21.5 & 16.7 & 19.4 \\
\hline & & $\mathrm{Me}$ & 33.3 & 36.1 & 0 & 0 & 3.2 & 0 & 2.3 \\
\hline & & $\operatorname{Pr} 25$. & 17.8 & 15.9 & 0 & 0 & 0 & 0 & 0 \\
\hline & & 75. & 57.5 & 66.7 & 1.6 & 0 & 10.6 & 12.2 & 6 \\
\hline \multirow{18}{*}{ C } & \multirow{9}{*}{$\begin{array}{r}\begin{array}{r}\text { Suicides under } \\
\text { intoxication } \\
\text { (completed) }(\mathrm{N}=4)\end{array}\end{array}$} & $M$ & 28.2 & 38.1 & 7.4 & 1.1 & 12.4 & 2.3 & 2.2 \\
\hline & & SE & 24 & 20.7 & 7.4 & 1.1 & 7.3 & 2.3 & 2.20 \\
\hline & & SD & 48 & 41.4 & 14.8 & 2.2 & 14.6 & 4.6 & 4.4 \\
\hline & & Range & 100 & 100 & 29.5 & 4 & 28.3 & 9.2 & 8.7 \\
\hline & & Min & 0 & 0 & 0 & 0 & 0 & 0 & 0 \\
\hline & & $\operatorname{Max}$ & 100 & 100 & 29.5 & 4 & 28.3 & 9.2 & 8.7 \\
\hline & & $\mathrm{Me}$ & 6.4 & 42.9 & 0 & 0 & 10.7 & 0 & 0 \\
\hline & & $\operatorname{Pr} 25$. & 1 & 9 & 0 & 0 & 0 & 0 & 0 \\
\hline & & 75. & 77.1 & 87.4 & 22.1 & 3.25 & 26.6 & 6.9 & 6.5 \\
\hline & \multirow{9}{*}{$\begin{array}{r}\text { Sober suicides } \\
(\text { completed) } \\
(\mathrm{N}=18)\end{array}$} & $M$ & 43.5 & 26.1 & 1.5 & 0.67 & 8.9 & 10.5 & 8.3 \\
\hline & & SE & 6.5 & 5.6 & 0.6 & 0.4 & 3.1 & 3.1 & 3.5 \\
\hline & & SD & 27.4 & 23.8 & 2.5 & 1.7 & 13.3 & 12.9 & 14.6 \\
\hline & & Range & 100 & 71.3 & 7.7 & 6 & 47.6 & 46.2 & 55.6 \\
\hline & & Min & 0 & 0 & 0 & 0 & 0 & 0 & 0 \\
\hline & & Max & 100 & 71.3 & 7.7 & 6 & 47.6 & 46.2 & 55.6 \\
\hline & & $\mathrm{Me}$ & 37.8 & 24.1 & 0 & 0 & 3.3 & 5.5 & 2.8 \\
\hline & & 25. & 19.7 & 4.9 & 0 & 0 & 0 & 0 & 0 \\
\hline & & 75. & 65.8 & 40.2 & 2.4 & 0 & 13.4 & 14.4 & 9.5 \\
\hline \multicolumn{10}{|c|}{$\begin{array}{l}\text { M - mean; SE - standard error; SD - standard deviation; } M e-\text { median; } \mathrm{Pr} . \text { - percentile } \\
{ }^{*} \text { Bold type - differences between groups are significant }(\mathrm{p}=.048) . \\
\text { Note: median scores used as more informative than means }\end{array}$} \\
\hline
\end{tabular}

Table 2: Average Ego State Levels in Comparison Groups 


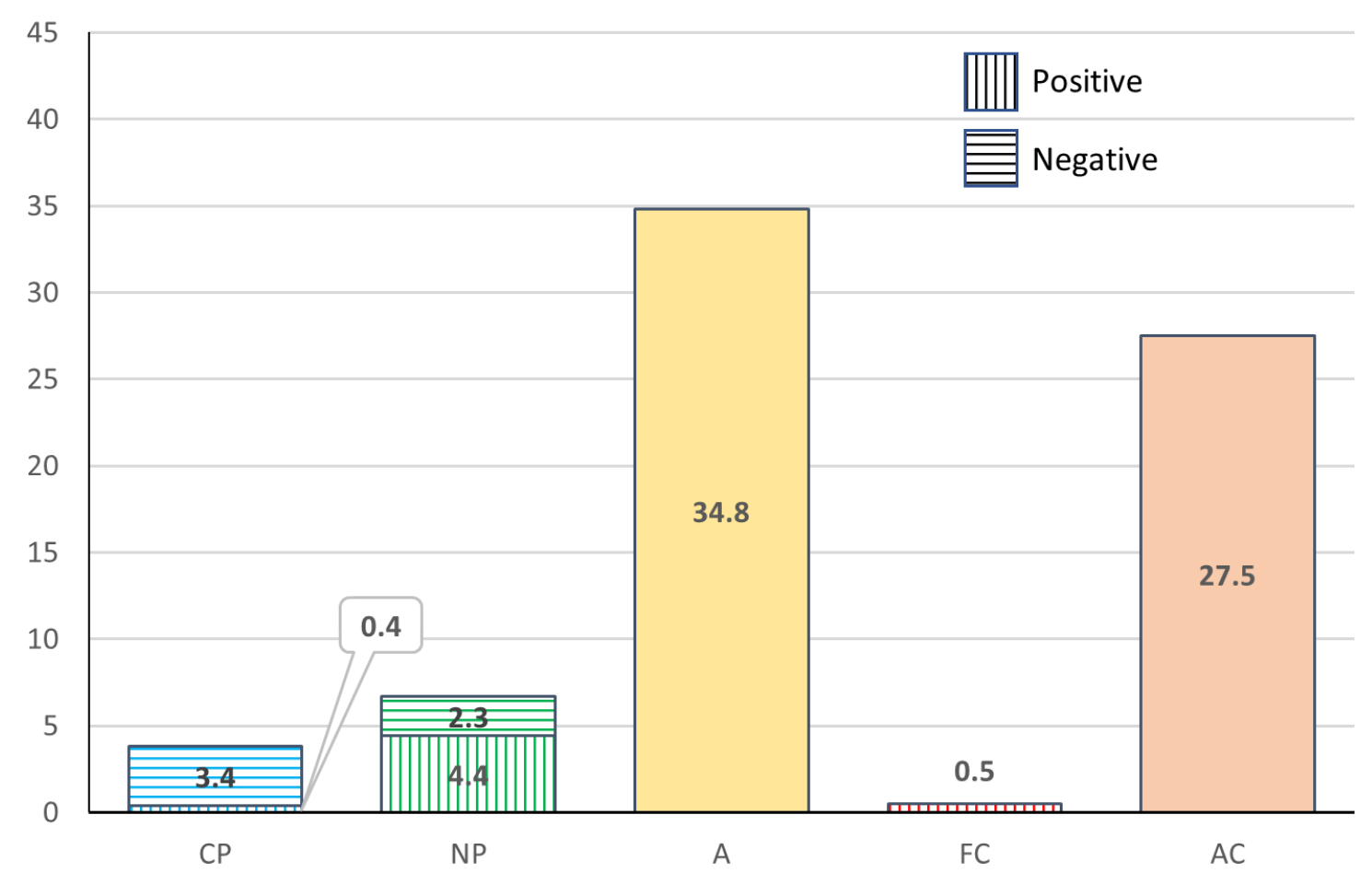

Figure 1: Completed Suicide Egogram

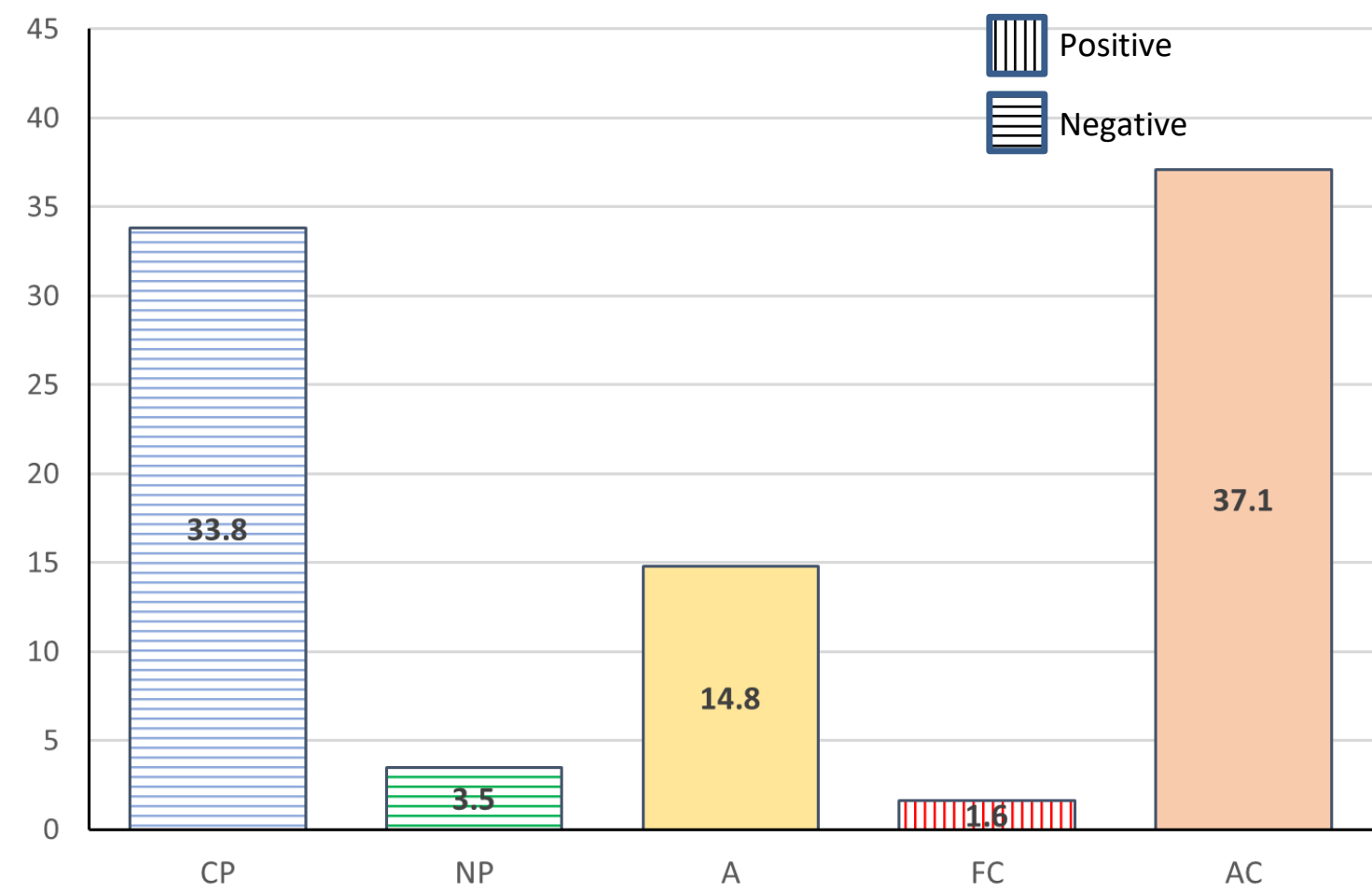

Figure 2: Attempted Suicide Egogram 


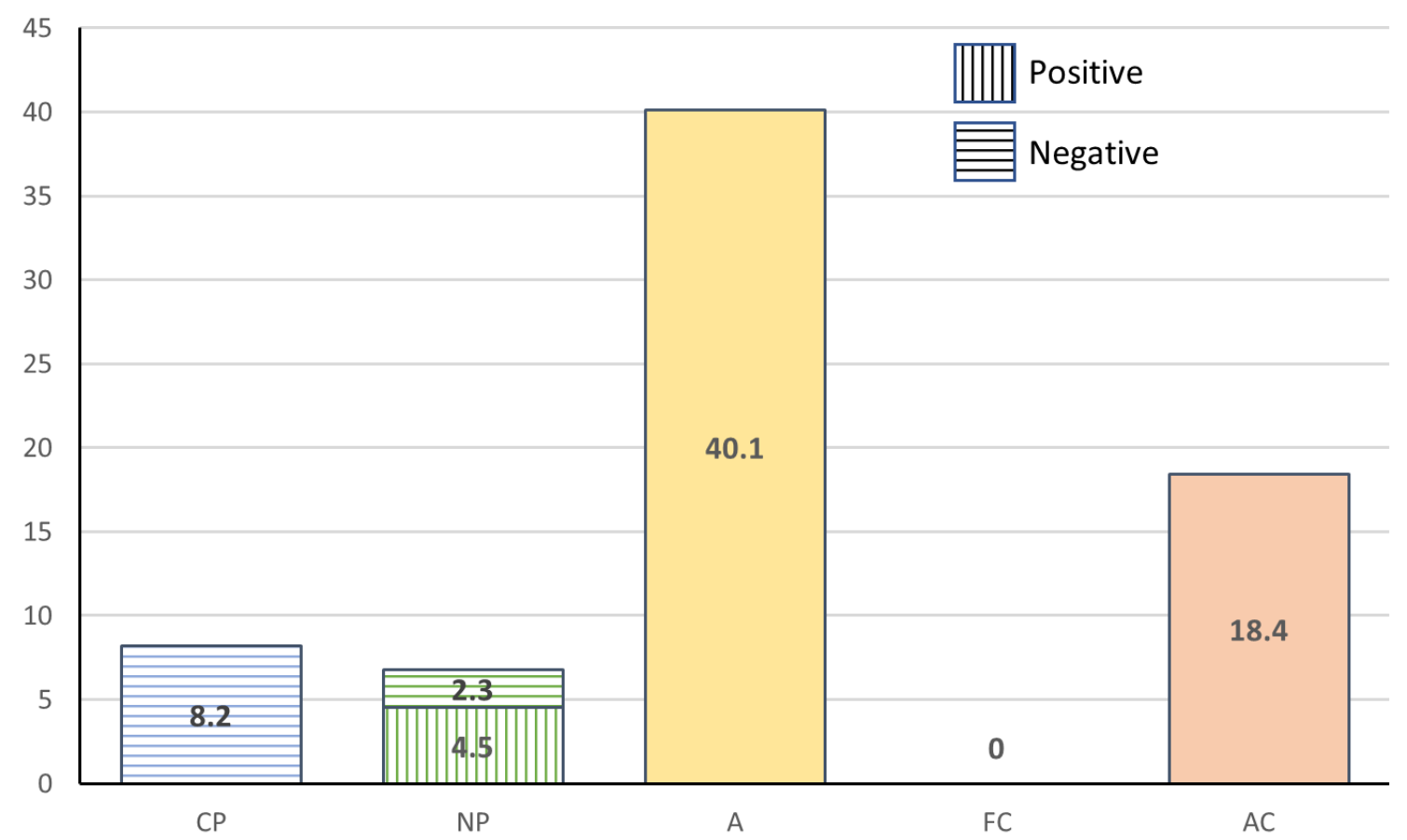

Figure 3: Alcoholic Suicide Egogram

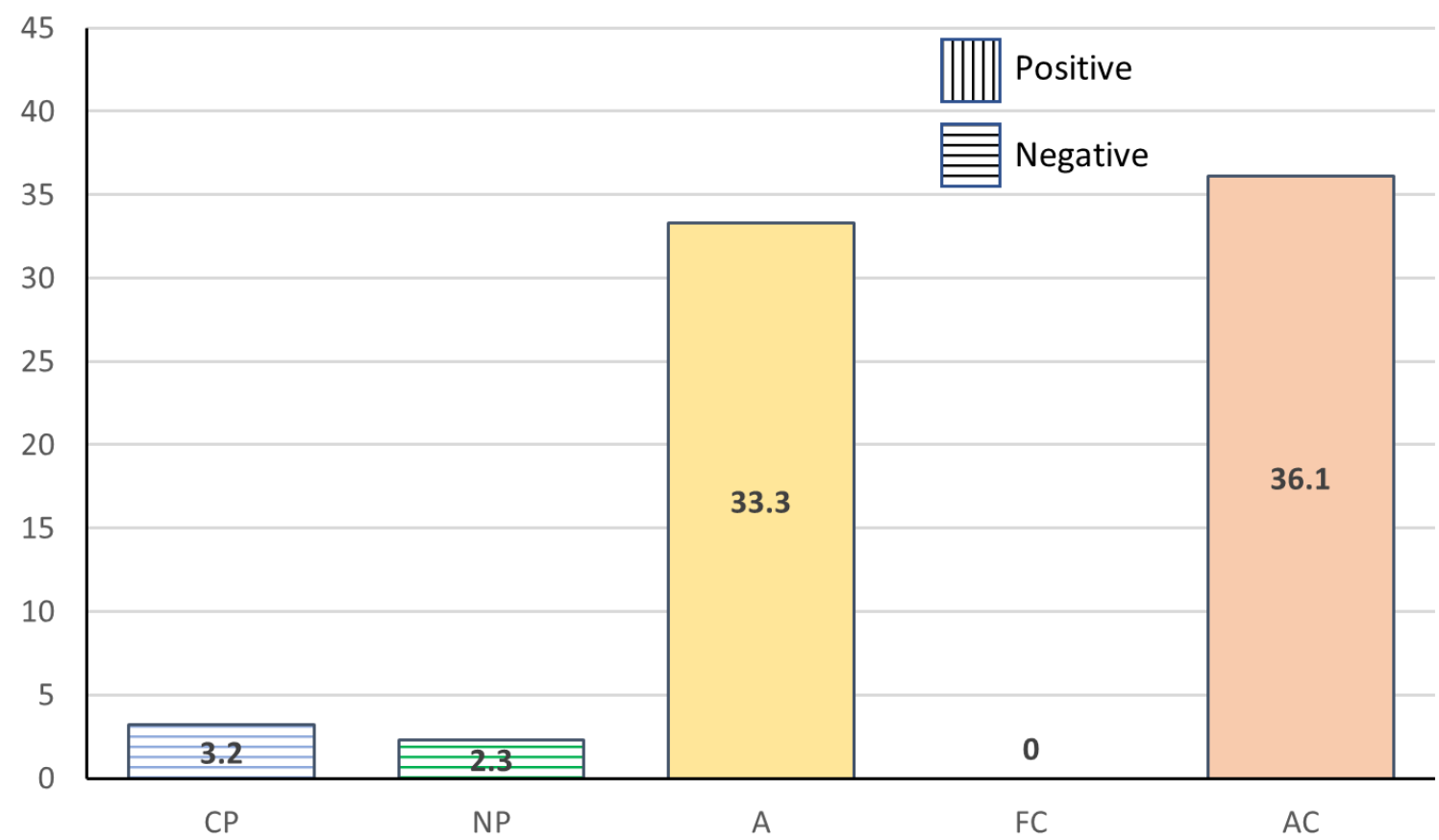

Figure 4: Non-Alcoholic Suicide Egogram 


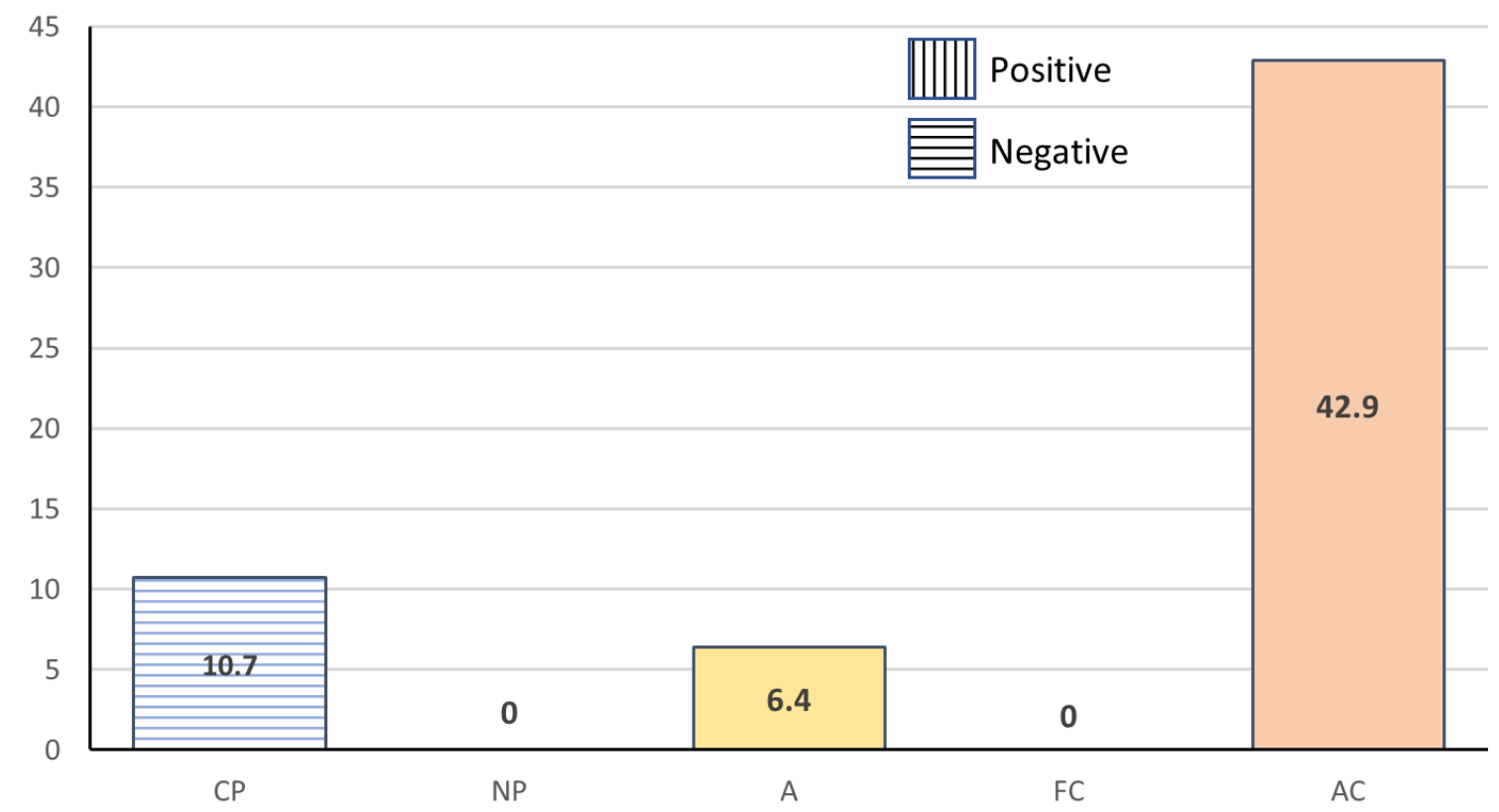

Figure 5: Intoxicated Suicide Egogram

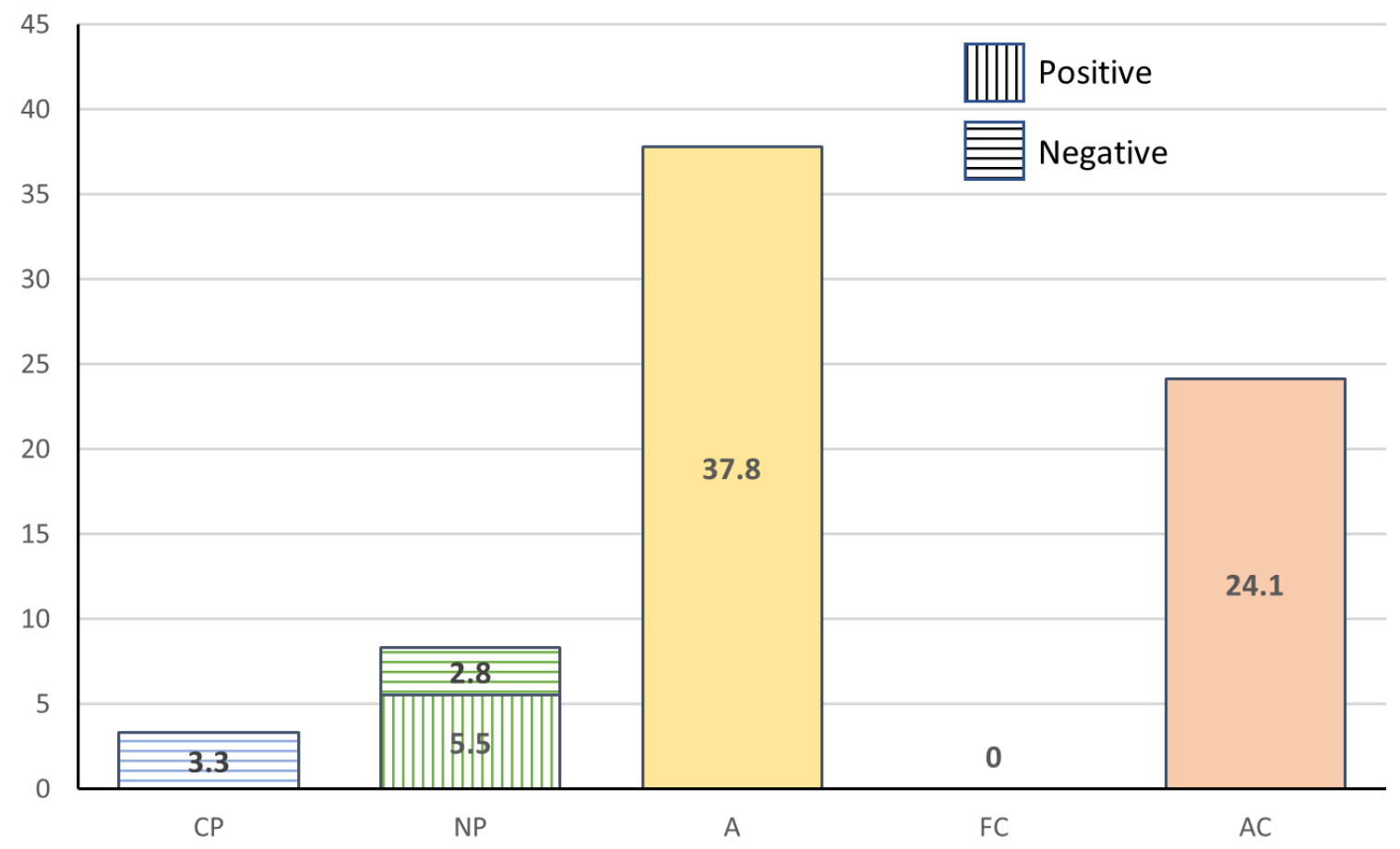

Figure 6: Sober Suicide Egogram 
Positive ego states: PCP; PNP; FC.

In line with our expectations, positive ego state levels were almost absent in the attempted suicides and were quite low in the completed suicides.

PNP manifested itself in three ways. For one thing, suicides expressed care for their relatives through arrangements to make funerals and dead body management easier for them ("I have taken a bath - I am clean"). For another thing, PNP acted to exonerate relatives from responsibility for suicide ("Don't blame anyone for my death"). Thirdly, suicides expressed concern for their beloved, children and grandchildren ("Don't forget about the kids, dear"; "Keep living, darling"; "Unless she gets married, treat her as family")

FC was present rarely and exclusively in men, especially when they addressed their beloved women in a note ("And I did love you"; "You are my nearest and dearest"; "And I want to live so much!").

Comparing alcohol-related egograms.

We found no statistically significant differences between alcoholic $(\mathrm{N}=13)$ and nonalcoholic suicide egograms $(\mathrm{N}=9)$, save for statistically insignificant trends towards higher NCP $(8.2 \%$ v $3.2 \%)$, PNP $(4.5 \%$ v $0 \%$ ) and lower AC (18.4\% v 36.1\%) levels in alcoholic suicides (Figures 3 and 4).

The autopsy revealed alcohol in blood or urine in only 3 suicides with AUD. In some suicide notes, individuals emphasised that they were sober at the moment of suicide, "Please blame no one for my death. I did that deliberately and was completely sober".

Comparing egograms of people who suicided under intoxication with alcohol $(\mathrm{N}=4)$, and sober suicides $(\mathrm{N}=18)$ yielded interesting results (Figures 5 and 6$)$. Intoxicated suicides' Adult (6.4\%) became less prominent as compared with sober suicides (37.8\%); however it remained high enough to make sure that the suicide attempt ended lethally $(p=.227)$. A complementary finding that Adult levels in the completed suicides remained higher than in the attempted suicides may also bear evidence to the Adult's active contribution to lethality of a suicide attempt.

As compared to the sober suicides, the intoxicated suicides tended to have higher levels of NCP $(10.7 \%$ v $3.8 \%)$ and $A C(42.9 \% \vee 24.1 \%)$. This exhibited in frequent accusations directed both inwards and outwards. Quite surprisingly, the intoxicated suicide egogram (Figure 5) with missing positive ego states, decathected Adult, heightened NCP and extremely high $\mathrm{AC}$, looked similar in these respects to the attempted suicide egogram (Figure 2).

\section{Discussion}

As we had expected, egograms of all comparison groups had relatively high levels of Adapted Child
(Figures 1 to 6). However the expected increase in AC rarely exceeded the threshold of $50 \%$ (only in $23 \%$ ( 6 people) of the whole sample). One interpretation of this finding may be that by maintaining a moderately high AC level, a suicidal individual may sustain the relevant level of unbearable psychological pain and suffering, and, simultaneously, allow other ego states to accumulate energy needed to carry out a killing that Menninger (1938) and Little (2009) wrote about. Our findings indicate that the perpetrator of the crime in lethal suicide attempts is Adult, whereas in non-lethal self-killings the individual falls prey to the 'syndicate' of negative Controlling Parent and Adult. In this sense, untreated severely depressed clients may paradoxically have a lower risk of suicide than those who have started pharmacological and/or psychotherapeutic treatment for depression. The highlycathected AC deprives a depressed individual of any resources that are prerequisite for planning and achieving the deadly goal and that recover as soon as the client starts getting treatment that helps. This is why the activation syndrome carries an elevated suicidal risk and needs to be watched carefully by practitioners (Culpepper, Davidson, Dietrich, Goodman, Kroenke \& Schwenk, 2004). Interestingly, Hillman (1976) believed that psychotherapy should maintain the state of 'analytical despair', precluding any hope for relief that the client may have: "This is an emptiness of soul and will. It is the condition present from that hour when, for the first time, the patient feels there is no hope at all for getting better, or even changing, whatsoever. An analysis led up to this moment and by constellating this despair lets free the suicidal impulse." (Hillman, p. 88).

As far as the role of the Adult ego state in the presuicidal state of mind is concerned, it seems that in completed suicides the Adult is investing in rational efforts to arrange both an individual's suicide and relatives' postsuicidal action. Comparison of the Adult levels in the completed and attempted suicides (Figures 1 and 2) showed a clinically significant difference that may reflect the Adult's contribution to suicide lethality. In addition, A was cathected even in intoxicated lethal suicides, although somewhat weaker than in sober ones.

Studies using the Suicidal Intent Scale (SIS) (Beck, Morris, Beck, 1974) indirectly support our assumption that the Adult plays the role of an efficient organiser and a consistent performer of a lethal suicide (Polewka, Mikołaszek-Boba, Chrostek Maj \& Groszek, 2005). Beck, Steer \& Trexler (1989) found that it was the SIS precautions subscale alone that differentiated those who did and did not eventually kill themselves. Eighteen people (of 161 patients who had been hospitalised because of a suicide attempt) who killed themselves during a follow-up period had taken more careful precautions against discovery at the time of 
their index attempts than nonsuiciders. Stefansson, Nordström \& Jokinen (2012) found that higher scores in the Planning subscale on SIS were a significant predictor of future suicide. Again, the attempters who eventually died because of suicide $(\mathrm{N}=7)$, had reported more planning at the time of their index attempt than the nonsuiciders $(\mathrm{N}=74)$. In a study of suicide notes left by children and adolescents (15 y.o. and younger), Freuchen \& Groholt (2013) found that the note writers emphasised that they were aware of what they were about to do, and left "an impression of control and of having thought things through;... they had also given away assets, done active preparations and ... they had exhibited an altered behaviour prior to suicide" (p. 9). Interestingly, in some studies, the tendency of adolescents to give specific instructions increased with age (Posener, Lahaye \& Cheifetz, 1989).

Based on his clinical observation, White (2011) argued that combination of high Adult and low Parent functioning in the presence of cathected Child was "the worst combination of all in terms of suicide risk" ( $p$. 142). Nevertheless, higher levels of Adult in completers' suicide notes may reflect usual levels of Adult functioning in suicide note writers as compared to non-note writers.

A reasonable question arises: why does Adult, which is being cathected throughout one's last hours and minutes before a suicide attempt, fail to avert suicidal plans and action? Indeed, although the suicidal individual's Adult seems to be reflecting a 'here-andnow' situation quite appropriately; and to be acting rationally and consistently to achieve the planned outcome, its activity appears to be rather irrational as it is their subjective reality that stipulates the appropriateness of suicide rather than objective circumstances. This ambiguity may explain the socalled cognitive constriction, which various authors believe to be a specific feature of the suicidal state of mind (Schneidman, 1998; Ringel, 1972; Pompili, Serafini, Innamorati, Dominici, Ferracuti, Kotzalidis, Serra, Girardi, Janiri, Tatarelli, Sher \& Lester, 2010). Cognitive constriction is a failure to consider alternative views on the situation and look for a different solution. In Berne's terms (Berne, 1964), the 'here-and-now' Adult ego state is not the same as the behavioural ego state that he also referred to as Adult but which he described as using behaviour like a computer (Hay, 2009). Hence, we need to shift to a different model of ego states in order to construe this phenomenon as reflecting contamination of (structural) Adult by (structural) Parental prejudice and (structural) Child illusions.

In order to prevent suicide, the therapist needs to avoid being conned by a calm and sensible appearance of clients who have just voiced a suicidal thought or plot. Although its levels are high, 'here-and-now' Adult is unable to fulfill its crucial function to ensure safe functioning and life protection. Therefore, decontamination needs to take place in a protective environment when the therapist, and the client's relatives or volunteers, can 'lend' their Adult to the client, e.g. by means of social control contracting (Loomis, 1982). From the TA perspective, during the decontamination work, the therapist stays in the Adult, investing efforts in avoiding any Parental attitudes which facilitate submissiveness and AC behaviours.

Comparison of the completed and attempted suicide egograms (Figures 1 and 2) revealed a statistically significant increase of NCP in the suicide survivors. It may relate to persecutory actions towards relevant others in 'dialogic' suicide attempts (Ambrumova, 1997). NCP's statements in the completed suicides targeted the individual's own self, and might have contributed to the feelings of psychache and hopelessness. $60 \%$ of suicide note-writers who killed themselves felt themselves a burden to relevant others (Fernández-Cabana, Ceballos-Espinoza, Mateos, Alves-Pérezc \& García-Caballero, 2015). The analysis of suicide-note themes revealed that the motive of selfblame was present in $65 \%$ of suicide notes from completed suicides as compared to $30 \%$ of attempted suicides (Brevard, Lester \& Yang 1990).

One way or another, the ego states of NCP and AC were exhibited in most letters. From the functional perspective, there is a close connection between these ego states as NCP facilitates AC behaviours and feelings. Suicide completers with this combination appeared to have reconciled with their fate and seemed to feel unable to change anything: "Forgive me for this. This is my fate"; "I have failed to become a good husband and father for you". This combination may as well have caused the depression that the suicidees were experiencing. Nevertheless, their depression had never reached the level of severity in which motor or cognitive inhibition could have precluded realisation of their intent to die.

Positive ego state levels in the presuicidal state of mind were very low. PCP was almost lacking in suicide completers, and was absent in attempted suicides, while it is PCP that contains structures that are relevant for survival such as positive parental guidance, social and religious attitudes, including a priori moral values. Therefore, Figures 1 and 2 illustrate lack of a moral conscience or the exclusion of the ego state that holds these attitudes.

At first glance, cathecting PCP and stimulating PCP activities might be quite appropriate in a therapeutic situation. However moral education - the essence of such work - is hardly appropriate during the crisis (all the more so as this kind of psychotherapy would be very time consuming and would mean creating a new $\mathrm{CP}$ with a new system of prohibitions in the suicidal 
individual's head). The work on actualizing a priori (i.e. independent of upbringing) vital attitudes and related feelings would be useful. Grof \& Halifax (1977) found that those who survived suicidal jumps from the Golden Gate Bridge, reported experiencing during their jump "spiritual rebirth and unity with other human beings, the entire universe, and God" (p. 152). Grof \& Halifax further noted: "As a result of their intimate encounter with death, some of them had a profound religious conversion; others described a reconfirmation of their previous religious beliefs" (p. 152).

Consistently with the earlier data, Little (2009) reported that the survivors of the Golden Bridge jumps had entered the water in a specific way, probably because "the moment they jumped they knew they had made a mistake" (p. 225). He also described a case of Kevin who survived his suicide attempt, and showed the slight, but nonetheless amazing, changes in Kevin's states of self in the morning of the attempt, immediately prior to suicide, and during the jump: “... he had left home, acting as if he was going to school ... kissed his father good-bye, thinking to himself, "He'll never see me again." When he arrived on the bridge, having stopped off for something to eat, ... he stood there for 40 minutes crying ... He then looked around and said to himself, "Fuck it, nobody cares." At that point Kevin hurdled over the railing, falling head first ... he was determined to die. But the moment he let go of the safety rail, he thought, "I don't want to die. What am I going to do? ... Kevin decided to ... enter the water feet first ..." (p. 225).

Ambrumova \& Postovalova (1983) quoted a suicidal woman's note, "Don't save me, I am of sound mind, I have done this deliberately..." At the end of the note, when the woman started to feel the drug effect, she scrawled, "Save me..." One may assume that PCP may actualise in the suicidal individual's head after the suicide note has been written, perhaps immediately during the suicide or at the time when there is little chance to change anything. Nevertheless, the suicide survivors' self-reports in our study allowed us to obtain no evidence to confirm that a suicide attempt (be it first or repeated one) might have a therapeutic effect. The well-known facts of a high probability of death as a result of a repeated suicide attempt (Beghi, Rosenbaum, Cerri \& Cornaggia, 2013) may be quite consistent with our findings.

PNP's position was quite limited, as there was always a risk of switching to NNP which would force the relatives into getting a gift that they simply 'couldn't refuse' (Mario Puzo, 1969). For example, at the beginning of a suicide note, a suicidal man was reproaching and cursing his wife, and later, when addressing his mother and relatives, he was saying something different about her, "Unless she gets married, treat her as family ". Another note, "Hang in there, son, don't worry about me. Mother"

Cathexis of FC seems likely to preclude any serious thinking about self-killing and death in general. In our study, rare cases of FC manifestations in men, i.e. spurs of genuine lack of understanding and resistance ("And I want to live so much!!? Very much"), failed to obtain support of positive Parental states ("I am striving for affection, warmth and love"), in contrast to Kevin's case. Genuineness, intimacy and spontaneity were not characteristic of the presuicidal state of mind in this study.

Comparison between alcoholic and nonalcoholic egograms revealed no statistically significant differences. However, almost all alcoholic egograms of completed suicides were characterised by Karpman's (1968) triad of Victim-Persecutor-Rescuer, which may evidence a continuing psychological game (Berne, 1961) with a suicidal death as a payoff. Furthermore, the motive of about $33.3 \%$ of alcoholic suicides was self-punishment.

The fact that only $3(23 \%)$ of 13 suicides with AUD were under intoxication during the suicide may relate to specific personality features of alcohol-dependent people. Berglund, Krantz \& Lundqvist (1987) found out that the presence of alcohol in blood during the autopsy correlated with brittleness while individuals with dysphoria most often had negative results.

Although alcohol in blood is found in 20 to $50 \%$ of all suicide cases in various cultures (Hayward, Zubrick \& Silburn 1992; Zerbini, de Carvalho Ponce, Mayumi Sinagawa, Barbosa Cintra, Romero Muñoz \& Leyton, 2012), positive Blood Alcohol Concentration (BAC) levels at autopsy may reflect incidental intake rather than alcohol use disorder (Brady 2006). Our study produced similar findings regarding the ratio of sober $(82 \%)$ to intoxicated suicides (18\%). O'Connell \& Lawlor (2005) summarised evidence that acute alcohol intake was a strong predictor of intentional injury (even stronger than alcohol dependence) and that it had been associated with use of more lethal suicide means and heightened suicide risk in the alcohol dependent. Pompilli et al. (2010) explored the complex relationship between alcohol use and suicidality and suggested that intoxication may trigger suicidality through disinhibition, impulsiveness and impaired judgment, as well as promoting depressive thoughts and feelings of hopelessness. It may contribute to the state of cognitive constriction, and relieve the distress associated with the act of selfkilling. They also provided a summary of Hufford's (2001) four psychological pathways for the relationship between acute alcohol use and suicidal behaviour: "(1) increasing psychological distress, including hopelessness, loneliness and depression; (2) enhancing or 
facilitating aggressive behaviour, including selfaggression; (3) changing an individual's expectations and helping to propel suicidal ideation into action; and (4) constricting attention and inhibiting effective coping strategies that would facilitate avoiding suicidal behaviour" (Pompilli et al. 2010, p. 1405).

These conceptualizations may in part be confirmed by our findings that the Adult levels in intoxicated suicides were lower than in abstinent individuals. This decline in Adult functioning might open the way to the impulsive action, but it was not enough to preclude the lethal outcome of an attempt. Interestingly, a current meta-analysis of alcohol-related risk of suicidal ideation, suicide attempt, and completed suicide (Darvishi, Farhadi, Haghtalab \& Poorolajal, 2015) found a consistent association between alcohol dependence and impulsive suicide attempts. In a Polish study of suicide attempts during heavy drinking episodes among individuals entering alcohol treatment (Klimkiewicz, Ilgen, Bohnert, Jakubczyk, Wojnar \& Brower, 2012), the most serious attempt was unplanned and committed mostly by men during a heavy drinking episode. Zerbini et al. (2012) speculated that the high mean BAC found in their study $(1.80 \mathrm{~g} / \mathrm{L})$ might reflect self-destructive behaviour associated with impulsiveness, which could lead to suicide. Interestingly, our study demonstrated that intoxicated suicides had higher levels of NCP as compared to sober ones which may reflect the elevated level of aggression (and autoagression) in intoxicated subjects. This combination of impulsivity (lowered $\mathrm{A}$; increased $\mathrm{AC}$ ) and aggression (increased NCP) has long been considered as representing a factor of heightened suicidal risk (Sher 2009).

It is worth mentioning that there are neurobiological theories that might explain the complicated relationship between suicide, alcohol, impulsivity and aggression. For example, based on Badawy's (1988) serotonin deficiency hypothesis of alcohol-induced aggressive behaviour, Brady (2006) argued that it was serotonergic dysfunction that was the common denominator in "this complex relationship" (p. 476).

From the therapeutic perspective, there may be an evident difference in the tactics of providing therapy to intoxicated and sober suicides, taking into account the Adult ego state levels in the two samples. Nevertheless, cognitive (decontamination) work with intoxicated individuals can hardly be underestimated as a 'here-and-now' Adult which remains contaminated may as well see the attempt through to a lethal final.

\section{Limitations.}

The small sample size may affect the power of the study, hence limiting the ability to generalise the findings beyond the study group. Nevertheless, small sample sizes in suicide note studies are quite usual as the incidence of note leaving rarely exceeds $20-38 \%$ in European cultures.

Some other design-related aspects of this study need certain improvement. Although its external validity is quite satisfactory as our findings have been consistent with the ideas and conceptualizations that have already been tested in quality scientific research, there may be some concerns regarding the internal validity of the study due to possible expert bias (one of the experts authored the concept of the script-based selfdestructive behaviours in alcoholics). The authors invested efforts to compensate for this bias by engaging two independent experts (PTSTA-P and CTA-P) who carried out additional assessment of the suicide notes in line with the proposed protocol.

The differences in completed and attempted suicides that we found may provide evidence for the construct validity of the proposed method of suicide note analysis as it has proved to be sensitive to the functional differences in the state of mind of different samples of suicidal individuals.

It should also be emphasised that the capacity of suicide note analysis as a unique instrument that allows an invaluable insight into last hours and minutes of suicidal individuals' existence needs in-depth further investigation.

As far as Berne's (1972) discrimination between structural and functional ego states are concerned, when analyzing the suicide note contents we were accounting for the behavioural and relational aspects (the function) as the notes addressed someone in all cases and, most likely, reflected long-standing behavioural roles, e.g. the drama triangle roles (Karpman, 1968) or other roles that the addressee might have been well aware of. We were also using our own responses to the note contents as some kind of markers, as Berne's (1961) social diagnosis. In order to investigate the structural aspect of the suicide notes or to draw a 'structural' egogram, a researcher would need to engage in historical and phenomenological diagnosis of ego states (Berne, 1961); they would need to be able to recognise and differentiate, for example, between Adult in Parent (A3), Adult (A2), or Adult in Child (A1). This kind of work is impossible without face-to-face therapeutic communication with the note writers.

\section{Conclusion}

The results of the suicide note analysis in this study may infer that the presuicidal functional activity is quite diverse, but by no means chaotic. When writing a note, reflecting on life and oneself, suicidal individuals cathect various, both positive and negative, structural and functional/behavioural personality units. Therefore, the individual's personality appears to be far from being constricted and inflexible. The notes written in 
one ego state represented only $13.8 \%$ of all cases. These findings may indicate that the therapist has an option of addressing positive personality structures while working with suicidal individuals who have recently attempted suicide, or may be communicating their suicidal intent (either directly or indirectly).

Our analysis highlighted the role of the Adult ego state, which dominated in the completed suicide notes, reflecting the state of mind immediately preceding lethal suicide attempts. High apparent Adult levels may reflect one's commitment and quite explicit lethal intent as well as the existence of a well-thought-out suicidal action plan.

In other words, the person who makes suicidal statements, but who seems to be level-headed, sensible, calm and able to appreciate the therapist's efforts, who speaks and acts without excessive emotion, may need more therapist's attention and observation than it may seem. This mechanism of Adult activation may underlie suicides of depressed patients whose affective symptoms have been reduced by antidepressants (this phenomenon is sometimes discussed in terms of activation syndrome (Culpepper, Davidson, Dietrich, Goodman, Kroenke \& Schwenk, 2004)).

As far as the evolution of the presuicidal state of mind is concerned, it appears that during the first stages, right after a triggering conflict or a suicidal insight, the individual cathects $A C$ and NCP, which manifest themselves mostly through emotion. Further on, when making a decision, Adult starts playing a stronger role as it provides a mental rationale to suicide and ensures that the suicidal action has been planned well enough so that the intent can be accomplished. Perhaps, during the last stages that the person is still aware of, they - urgently but often inefficiently - may cathect Parental defensive mechanisms (moral or religious).

Lack of significant differences between alcoholic and non-alcoholic suicides as far as the ego state levels are concerned, may reflect the existence of shared intrapersonal processes and mechanisms that aim at committing a fatal suicide.

The findings of our study may be useful for developing therapeutic tactics when working with suicidal individuals. Despite some differences between alcoholic and nonalcoholic completed suicides, the ego states that were involved during the last presuicidal stage were essentially similar, which may imply that suicidal phenomena share common psychodynamics.

The findings regarding a crucial difference in the suicidal state of mind in suicide attempters who eventually killed themselves and those who stayed alive may indicate that suicide survivors had used no behaviours or actions that would have helped them to develop and maintain a highly lethal intent or to arrange for a 'successful' implementation of a suicidal plot.

The study also revealed that suicide survivors presented a wide range of manipulative transactions that often had the nature of a psychological game, in which the main motive of alcoholic completed suicides appeared to be self-punishment.

The finding that alcoholic intoxication affects the suicidal state of mind is somewhat controversial. On the one hand, a decline in Adult functioning (which is responsible for successful implementation of the suicidal plan) may be regarded as having some positive, preventive implications. On the other hand, this idea is hardly consistent with the findings of other studies, especially that acute alcohol intake tends to elevate the suicide risk. Intoxication may introduce a specific psychological game motive into the suicidal state of mind of an intoxicated person, bringing their suicidal state of mind closer to the mental state of a suicide survivor.

Dmitri I. Shustov MD, PhD is a Teaching and Supervising Transactional Analyst (Psychotherapy) and Professor and Chair of the Department of Psychiatry of the I. P. Pavlov Ryazan State Medical University. His professional interests focus on research and treatment of substance use disorders and self-destructive behaviour. He can be reached on dmitri shustov@mail.ru

Olga D. Tuchina is a psychologist and a researcher in the Psychotherapy, Psychology and Rehabilitation Department of the Moscow Treatment and Research Centre for Substance Use Disorders. She can be reached on shtuchina@gmail.com.

Tatiana V. Agibalova MD, PhD is a Certified Transactional Analyst (Psychotherapy) and Chair of the Psychotherapy, Psychology and Rehabilitation Department of Moscow Treatment and Research Centre for Substance Use Disorders. She can be reached on agibalovatv@mail.ru.

Nadezhda L. Zuykova MD, PhD is a Provisional Teaching and Supervising Transactional Analyst (Psychotherapy) and Chair of the Psychiatry, Psychotherapy and Psychosomatic Pathology Department, the Faculty of Continuous Medical Education of the People's Friendship University of Russia. She can be reached on znl@yandex.ru.

\section{References}

Ambrumova, Aina G. \& Postovalova, L.I. (1983) Semejnaja diagnostika $v$ suicidologicheskoj praktike [Family assessment in suicidology]. Moscow: Medicine. 
Ambrumova, Aina G. (1997). Psihologija samoubijstva [Psychology of suicide]. Social'naja i klinicheskaja psihiatrija [Social \& Clinical Psychiatry]. 4, 14-20

Badawy, Abdulla A.-B. (1998). Alcohol, aggression and serotonin: metabolic aspects. Alcohol \& Alcoholism, 33(1), 66-72

Beck, Roy W., Morris, Jeffrey B. \& Beck, Aaron T. (1974). Cross-validation of the suicidal intent scale. Psychological Reports. 34(2), 445-446. doi:10.2466/pr0.1974.34.2.445.

Beck, Aaron T., Steer, Robert A. \& Trexler, Larry D. (1989). Alcohol abuse and eventual suicide: A 5- to 10-year prospective study of alcohol-abusing suicide attempters. Journal of Studies on Alcohol, 50(3), 202-209. http://dx.doi.org/10.15288/isa.1989.50.202.

Beghi, Massimiliano, Rosenbaum, Jerrold F, Cerri, Cesare, Cornaggia, Cesare M. (2013). Risk factors for fatal and nonfatal repetition of suicide attempts: a literature review. Neuropsychiatric Disease and Treatment, 9, 1725-1736. doi:10.2147/NDT.S40213.

Berglund, Mats, Krantz, Peter \& Lundqvist, Gunilla. (1987). Suicide in alcoholism. Acta Psychiatrica Scandinavica, 76(4), 381-385. doi:10.1111/j.1600-0447.1987.tb05622.x.

Berne, Eric. (1961). Transactional analysis in psychotherapy: A systematic individual and social psychiatry. New York, NY: Grove Press.

Berne, Eric (1964) Games People Play, New York: Grove Press

Berne, Eric. (1972) What Do You Say After You Say Hello? New York: Grove Press

Brady, John (2006). The association between alcohol misuse and suicidal behavior. Alcohol and Alcoholism, Volume 41, Issue 5, 1. 473-478. https://doi.org/10.1093/alcalc/agl060.

Brevard, Alison, Lester, David, Yang, Bijou. (1990). A comparison of suicide notes written by suicide completers and suicide attempters. Crisis, 11, 7-11.

Callanan, Valerie J. \& Davis, Mark S. (2009). A comparison of suicide note writers with suicides who did not leave notes. Suicide and Life-Threatening Behavior, 39(5), 558-568. doi:10.1521/suli.2009.39.5.558.

Campbell, Donald. (1999). The role of the father in a presuicide state. In R. J. Perelberg (Ed.), Psychoanalytic understanding of violence and suicide (pp. 75-86). London: Routledge.

Carpenter, Belinda, Bond, Christine Tait, Gordon, Wilson, Moira \& White, Kris. (2016). Who leaves suicide notes? An exploration of victim characteristics and suicide method of completed suicides in Queensland. Archives of Suicide Research, 20(2), 176-190. doi:10.1080/13811118.2015.100449.

Cerel, Julie, Moore, Melinda, Brown, Margaret M., van de Venne, Judy \& Brown, Sabrina L. (2014). Who leaves suicide notes? A six-year population-based study. Suicide and Life-Threatening Behavior, 45(3), 326-334. doi:10.1111/sltb.12131.

Culpepper, Larry, Davidson, Jonathan R. T., Dietrich, Allen J., Goodman, Wayne K., Kroenke, Kurt \& Schwenk, Thomas L. (2004). Suicidality as a possible side effect of antidepressant treatment. Primary Care Companion to The Journal of Clinical Psychiatry, 6(2), 79-86.

Darvishi, Nahid, Farhadi, Mehran, Haghtalab, Tahereh \& Poorolajal, Jalal. (2015). Alcohol-related risk of suicidal ideation, suicide attempt, and completed suicide: a metaanalysis. PLOS ONE, 10(5), e0126870. doi:10.1371/journal.pone.0126870.

Drye, Robert C., Goulding, Robert L. \& Goulding, Mary E. (1973). No-suicide decisions: patient monitoring of suicidal risk. American Journal of Psychiatry, 130(2), 171-174. doi:10.1176/ajp.130.2.171

Dusay, John M. (1977) Egograms: How I see you and you see me. New York: Harper\&Row.

Fernández-Cabana, Mercedes, Ceballos-Espinoza, Francisco, Mateos, Raimundo, Alves-Pérez, María Teresa \& García-Caballero, Alejandro Alberto (2015). Suicide notes: clinical and linguistic analysis from the perspective of the Interpersonal Theory of Suicide. The European Journal of Psychiatry, 29(4), 293-308. doi:10.4321/s021361632015000400006 .

Freuchen, Anne \& Grøholt, Berit (2013). Characteristics of suicide notes of children and young adolescents: An examination of the notes from suicide victims 15 years and younger. Clinical Child Psychology and Psychiatry, 20(2), 194-206. doi:10.1177/1359104513504312.

Gabbard, Glen. (2003). Miscarriages of psychoanalytic treatment with suicidal patients. International Journal of Psychoanalysis, 84, 249-261. doi: 10.1516/WEDV-CUFA9T91-ELDY.

Grof, Stanislav \& Halifax, Joan (1977). The Human Encounter with Death. New York: E.P. Dutton.

Haines, Janet, Williams, Christopher L. \& Lester, David. (2011). The characteristics of those who do and do not leave suicide notes: is the method of residuals valid? OMEGA - Journal of Death and Dying, 63(1), 79-94. doi:10.2190/om.63.1.d.

Handelman, Lori D. \& Lester, David. (2007). The content of suicide notes from attempters and completers. Crisis, 28(2), 102-104. doi:10.1027/0227-5910.28.2.102.

Hay, Julie (2009). Transactional Analysis for Trainers. $2^{\text {nd }}$ edition. Hertford: Sherwood Publishing.

Hayward, Linda, Zubrick, Stephen R., Silburn, Sven. (1992) Blood alcohol levels in suicide cases. Journal of Epidemiology \& Community Health, 46(3), 256-260. doi:10.1136/jech.46.3.256. 
Hillman, James. (1976). Suicide and the Soul. Zurich, Switzerland: Spring Publications.

Holloway, William. (1973). Shut the escape hatch. Monograph IV, 15-18. W. Holloway, publisher.

Hufford, M. (2001). Alcohol and suicidal behavior. Clinical Psychology Review, 21, 797-811.

Jager-Hyman, Shari, Cunningham, Amy, Wenzel, Amy, Mattei, Stephanie, Brown, Gregory K. \& Beck, Aaron T. (2014). Cognitive distortions and suicide attempts. Cognitive Therapy and Research, 38(4), 369-374. doi:10.1007/s10608-014-9613-0.

Jekkel, Éva \& Tringer, László. (2004). Suicide and cognitive distortions. Horizons of Psychology. 13, 139-150.

Joiner, Thomas E., Pettit, Jeremy W., Walker, Rheeda L., Voelz, Zachary R., Cruz, Jacqueline, Rudd, M. David \& Lester, David. (2002). Perceived burdensomeness and suicidality: two studies on the suicide notes of those attempting and those completing suicide. Journal of Social and Clinical Psychology, 21(5), 531-545. doi:10.1521/jscp.21.5.531.22624.

Karpman, Stephen. (1968). Fairy tales and script drama analysis. Transactional Analysis Bulletin, 7(26), 39-43.

Klimkiewicz, Anna, Ilgen, Mark A., Bohnert, Amy S.B., Jakubczyk, Andrzej, Wojnar, Marcin \& Brower, Kirk J. (2012). Suicide attempts during heavy drinking episodes among individuals entering alcohol treatment in Warsaw, Poland. Alcohol and Alcoholism, 47(5), 571-576. doi:10.1093/alcalc/ags069.

Lakeman, Richard \& FitzGerald, Mary. (2008). How people live with or get over being suicidal: a review of qualitative studies. Journal of Advanced Nursing, 64(2), 114-126. doi:10.1111/j.1365-2648.2008.04773.x.

Leennaars, Antoon A. (1988). Suicide notes. NY, New York. Human Science Press.

Leennaars, Antoon A. (1989). Suicide across the adult lifespan: an archival study. Crisis. 10, 152-163.

Leenaars, Antoon A. (2010) Edwin S. Shneidman on Suicide. Suicidology Online, 1, 5-18.

Leennars, Antoon A., Lester, David, Lopatin, Andrew A., Shustov, Dmitri I., Wenckstern, Susanne. (2005). Analiz predsmertnykh zapisok iz Rossii i Sojedinennykh Shtatov [Analyzing suicide notes from Russia and the USA]. Social'naya i klinicheskaya psihiatriya [Social \& Clinical Psychiatry], 3, 22-28.

Lester, David (2009). Theories of attempted suicide: should they differ from theories of completed suicide. Clinical Neuropsychiatry, 6(4), 188-191.
Lester, David \& Gunn III, John F. (2012) Perceived burdensomeness and thwarted belonging: an investigation of the interpersonal theory of suicide. Clinical Neuropsychiatry, 9(6), 221-224.

Little, Ray. (2009). Understanding the psychodynamics of suicidal clients: Exploring suicidal and presuicidal states. Transactional Analysis Journal, 39, 219-228. doi:10.1177/036215370903900305.

Loomis, Maxine. (1982). Contracting for change. Transactional Analysis Journal, 12(1), 51-55. doi:10.1177/036215378201200107.

Menninger, Karl. (1938). Man against himself. New York: Harcourt Brace \& World.

Nock, Matthew K. \& Kessler, Ronald C. (2006). Prevalence of and risk factors for suicide attempts versus suicide gestures: Analysis of the National Comorbidity Survey. Journal of Abnormal Psychology, 115(3), 616-623. doi:10.1037/0021-843x.115.3.616.

O'Carroll, P. W., Berman, A. L., Maris, R. \& Moscicki, E. (1996). Beyond the tower of Babel: A nomenclature for suicidology. Suicide \& LifeThreatening Behavior, 26, 237252.

O'Connell, Henry \& Lawlor, Brian A. (2005). Recent alcohol intake and suicidality - a neuropsychological perspective. Irish Journal of Medical Science, 174(4), 51-54. doi:10.1007/bf03168983.

O'Connor, Rory C. \& Leenaars, Antoon A. (2004). A thematic comparison of suicide notes drawn from Northern Ireland and the United States. Current Psychology, 22(4), 339-347. doi:10.1007/s12144-004-1039-5.

O'Donnell, lan, Farmer, Richard \& Catalan, Jose. (1993). Suicide notes. British Journal of Psychiatry, 163(01), 45-48. doi:10.1192/bjp.163.1.45.

Paraschakis, Antonios, Michopoulos, loannis, Douzenis, Athanassios, Christodoulou, Christos, Koutsaftis, Filippos \& Lykouras, Lefteris. (2012). Differences between suicide victims who leave notes and those who do not. Crisis, 33(6), 344-349. doi:10.1027/0227-5910/a000150.

Pestian, John P., Matykiewicz, Pawel \& Linn-gust, Michelle (2012). What's in a note: construction of a Suicide Note Corpus. Biomedical informatics insights, 5(1), 1-6 doi: $10.4137 /$ BII.S10213.

Pestian, John, Nasrallah, Henry, Matykiewicz, Pawel, Bennett, Aurora \& Leenaars, Antoon A. (2010). Suicide note classification using natural language processing: a content analysis. Biomedical Informatics Insights, 3, BII.S4706. doi:10.4137/bii.s4706.

Platt, Stephen D. (1985). A subculture of parasuicide? Hum Relat, 38: 257-97. doi: 10.1177/001872678503800401. 
Polewka, Andrzej, Mikołaszek-Boba, Magdalena, Chrostek Maj, Jan, Groszek, Barbara. (2005). The characteristics of suicide attempts based on the Suicidal Intent Scale scores. Przegl Lek. 62(6), 415-8.

Pompili, Maurizio, Serafini, Gianluca, Innamorati, Marco, Dominici, Giovanni, Ferracuti, Stefano, Kotzalidis, Giorgio D., Serra, Giulia, Girardi, Paolo, Janiri, Luigi, Tatarelli, Roberto, Sher, Leo \& Lester, David. (2010). Suicidal behavior and alcohol abuse. Int. J. Environ. Res. Public Health. 7, 1392-1431; doi:10.3390/ijerph7041392.

Posener, Joel A., Lahaye, André \& Cheifetz, Philip N. (1989). Suicide notes in adolescence. The Canadian Journal of Psychiatry, 34(3), 171-176. doi:10.1177/070674378903400302.

Puzo, Mario (1969) The Godfather New York: GP Putnam's Sons

Ringel, Erwin. (1976). The presuicidal syndrome. Suicide and Life-Threatening Behavior. 6, 379-394.

Schustov, Dmitri I. (1997). A psychotherapeutic process by letter: the confidence post. Transactional Analysis Journal, 27(3), 224-227. doi:10.1177/036215379702700312.

Schustov, Dmitri I. \& Lester, David. (1999). Counseling the suicidal client by letter. Crisis, 20(3), 127-131. doi.org/10.1027//0227-5910.20.3.127.

Sher, Leo. (2009). Aggression, suicidal behavior, and the concept of post-traumatic mood disorder. Psychiatry and Clinical Neuroscience 63(2), 254-255 doi.org/10.1111/j.1440-1819.2008.01919.x

Shioiri, Toshiki, Nishimura, Akiyoshi, Akazawa, Kohei, Abe, Ryo, Nushida, Hideyuki, Ueno, Yasuhiro, Kojika-Maruyama, Maki, Someya, Toshiyuki, T. (2005). Incidence of noteleaving remains constant despite increasing suicide rates. Psychiatry and Clinical Neurosciences, 59(2), 226-228. doi:10.1111/j.1440-1819.2005.01364.x.

Shneidman, Edwin S. (1985). Definition of suicide. New York: John Wiley \& Sons.

Shneidman, Edwin S. (1998). The suicidal mind. New York: Oxford University Press.

Shneidman, Edwin S. (2005). Anodyne psychotherapy for suicide: a psychological view of suicide. Clinical Neuropsychiatry: Journal of Treatment Evaluation, 2(1), 712.

Shustov, Dmitri I. (2000). Autoagressivnoe povedenie I alkogolizm (Kliniko-terapevticheskoe issledovanie) [Selfdestructive behaviour and alcoholism: clinical and therapeutic study]: Doctor of Medical Science Thesis; Psychiatry, Addiction Medicine. Ryazan, Ryazan State Medical University. [in Russian].

Shustov, Dmitri I. (2005). Autoagressija, suicid i alkogolizm [Self-destructiveness, Suicide and Alcoholism]. Moscow: Cogito-Center. [in Russian].
Shustov, Dmitri I., Tuchina, Olga D., Novikov, Sergey A. \& Fedotov, llya A. (2016). Combinations of injunctions and personality types determining forms of self-destructive behaviour in alcohol-dependent clients: Findings of a Russian observational study. International Journal of Transactional Analysis Research, 7(2), 10-20. doi:10.29044/v7i2p10.

Sinyor, Mark, Schaffer, Ayal, Hull, lan, Peisah, Carmelle \& Shulman, Kenneth. (2015). Last wills and testaments in a large sample of suicide notes: Implications for testamentary capacity. British Journal of Psychiatry, 206(01), 72-76. doi:10.1192/bjp.bp.114.145722.

Skogman Pavulans, Katarina, Bolmsjö, Ingrid, Edberg, Anna-Karin \& Öjehagen, Agneta. (2012). Being in want of control: Experiences of being on the road to, and making, a suicide attempt. International Journal of Qualitative Studies on Health and Well-Being, 7(1), 16228.

doi:10.3402/qhw.v7i0.16228.

Stack, Steven \& Rockett, lan R. H. (2016). Are suicide note writers representative of all suicides? Analysis of the National Violent Death Reporting System. Suicide and LifeThreatening Behavior. doi:10.1111/sltb.12320.

Stefansson, Jon, Nordström, Peter \& Jokinen, Jussi. (2012). Suicide Intent Scale in the prediction of suicide. Journal of Affective Disorders, 136(1-2), 167-171.

doi:10.1016/j.jad.2010.11.016.

Steiner, Claude. (1974). Games alcoholics play: The analysis of life scripts. New York, NY: Ballantine Books.

Stewart, Ian \& Joines, Vann. (2012) TA Today. A new introduction to Transactional Analysis. $2^{\text {nd }}$ edition Nottingham and Chapel Hill: Lifespace Publ.

Taylor, Steve. (1982). Durkheim and the study of suicide. London, UK: Macmillan.

Tilney, Tony. (1998). Dictionary of Transactional Analysis. London, Whurr Publishers Ltd.

Valach, Ladislav, Young, Richard A. \& Michel, Konrad. (2011) Understanding suicide as an action. In K. Michel, D.A. Jobes (Eds), Building a therapeutic alliance with the suicidal patient. Washington, DC, US: American Psychological Association. 129- 148. doi:10.1037/12303008.

White, Tony. (2011). Working with suicidal individuals: a guide to providing understanding, assessment and support. London: Jessica Kingsley.

White, Tony. (2017). A Transactional Analysis perspective on suicide risk assessment. Transactional Analysis Journal, 47(1), 32-41. doi:10.1177/0362153716674683.

Zerbini, Talita, de Carvalho Ponce, Julio, Mayumi Sinagawa, Daniele, Barbosa Cintra, Raquel, Romero Muñoz, Daniel \& Leyton, Vilma. (2012). Blood alcohol levels in suicide by hanging cases in the state of Sao Paulo, Brazil. Journal of Forensic and Legal Medicine, 19(5), 294-296. doi:10.1016/j.jlm.2012.02.022. 